\title{
Dentistry and the fight against discrimination
}

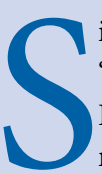
ir, I write in regards to the article 'What are you?'1 With the Black Lives Matter (BLM) movement, many articles have been published in relation to the topic aiming to raise awareness of what minority groups face on a day-to-day basis. Micro-aggressive comments including people questioning our ethnic backgrounds often feature. I may be of the minority but the question 'where are you actually from?' doesn't tend to bother me unless said with racial intent. I will confidently say I am not originally from British heritage as I believe each culture, ethnicity and race should be appreciated and one should not feel out of place for not being originally British. Questions often show peoples' interest in learning about our backgrounds, especially in such a progressive society. On the occasion it's used with racial intent I've tried to see this as a positive teaching moment. Every positive contact a patient has with people of colour and minority groups will help reduce prejudice and may reduce future racial incidences. Which poses the question, are we as dental professionals able to help combat discrimination and racism? - I believe we are.

How you may ask? I think it's simple, we are in a strong position with our comfortable one-to-one setting as opposed to group settings. Patients feel less hesitant to ask questions when there are fewer people to misconceive/judge their questions. Dentistry is a field with such diverse backgrounds of professionals. Despite the profession still being predominately white dominated the percentage of other ethnic groups entering the field is rising. The GDC released information on the breakdown of ethnicities of their registrants. In July 2020, 51\% of Dentists registered were of purely white backgrounds and $36.5 \%$ were of other ethnic backgrounds such as South Asian, Chinese, Black or mixed backgrounds. Some applicants did not disclose their ethnicity (12.5\%). ${ }^{2}$ Between 2010-2014, British Asians made up around $37 \%$ of those accepted into UK dental schools. ${ }^{3}$ When analysing the Universities and Colleges Admissions Service (UCAS) yearly applicants, there is an increase in annual applicants from Asian and Black groups compared to White British applicants which has plateaued. ${ }^{4}$ This shows it is highly likely patients will encounter someone from a minority ethnic background during their lifetime of dental treatment, increasing opportunities to raise awareness.

'Why do you wear that on your head?' is one of the most frequent questions I get asked as a Muslim dentist wearing a headscarf. I take this as an opportunity to educate those asking. Ignorance and preconceived views of different religions and cultures are often the reasons behind discrimination against minority groups and those of different faiths/backgrounds. Assumptions and misconceptions of religion, race etc often lead to society attacking these groups on false pretences. Therefore, when asked about religion, I believe it's my job to help counteract these common misconceptions. Who better than someone within that religious group who can present it positively and factually? You may think, surely within our modern society people should know better? Well yes ideally, but unfortunately, we don't live in a perfect world and it's become every educated person's role to help fight against discrimination by passing on their knowledge to those who may be ignorant.

\section{'Ignorance and preconceived views of different religions and cultures is often the reason behind discrimination against minority groups and those of different faiths/ backgrounds'}

I have lived with people of many backgrounds and cultures, four different nationalities in total. I learnt about different traditions, foods, common religions and more. I wouldn't have learnt as much without asking. Had I been made to feel my inquisitive nature came across as microaggressive I would still be very ignorant. Allow people to ask and learn. With that being said, we mustn't feel that we need to justify our decisions, opinions or beliefs. A small majority of individuals will attempt to enforce their own opinions or belittle our beliefs, therefore there must be boundaries to when we accept questioning. As long the inquisition is to gain information, said without malicious intent and helps reduce misunderstandings, we should be as open as possible.

We all have our own opinions on what we find offensive and we should hope that everyone respects that. We all want to live our lives happy and content without constantly being questioned; but the reality is, in a white, British dominated country our appearance is different. "But where are you actually from?' and how many of you who have been asked this question are white?' In response to this, it is expected that we be the ones questioned about our origin as opposed to white people as we are the minority in this country. Similarly, when I visit my home country, I hear the same question being asked to people who are from a white background. These questions aren't only asked to those who visibly look different, but also those who sound different. Britain has become a melting pot of cultures therefore there are many of us with accents from around the world. Yes, we are British, but we also have a rich heritage that we should be proud to discuss, proud to share. It's time we don't shy away from this, embrace our differences and appreciate what we have to offer. If people avoid asking us questions out of fear of being offensive, when will people learn how amazing each and every background is? Let people ask, and be ready to answer with happiness, positivity and excitement! The world is ready for us...

Dr K. Via email

\section{References}

1. Jamil, H. What are you? BDJ In Pract 2020; 33: 4.

2. GDC. 2020. Request for datasets of ethnicity of registrants number and percentage. General Dental Council. [Online]. Available at: https:// www.gdc-uk.org/about-us/freedom-ofinformation/information-released-under-thefoi-act [Accessed: $22^{\text {nd }}$ August 2020]

3. Gallagher J E, Calvert A, Niven V, Cabot L. Do high tuition fees make a difference? Characteristics of applicants to UK medical and dental schools before and after the introduction of high tuition fees in 2012. Br Dent J 2017; 222: 181-190.

4. UCAS. 2020. Applicant releases for 2020 cycle. UCAS. [Online]. Available at: https://www.ucas. com/data-and-analysis/ucas-undergraduatereleases. [Accessed: $22^{\text {nd }}$ August 2020.] 